\title{
EDUKASI PADA IBU HAMIL, KELUARGA DAN KADER POSYANDU TENTANG PENCEGAHAN STUNTING
}

\author{
Sukmawati, Yanti Hermayanti, Furkon Nurhakim, Iceu Amira DA dan Henny Suzana Mediani \\ Fakultas Keperawatan Universitas Padjadjaran \\ E-mail: sukmawati@unpad.ac.id
}

\begin{abstract}
ABSTRAK. Stunting merupakan salah satu masalah gizi kronis yang terjadi pada anak balita yang disebabkan kurangnya asupan nutrisi dalam waktu yang lama. Stunting berdampak mudah terkena penyakit, tidak optimalnya perkembangan kognitif, motorik dan verbal, postur tubuh, kapasitas belajar, performa saat usia sekolah, produktifitas, kapasitas kerja, meningkatnya obesitas dan penyakit lain serta menurunnya sistem reproduksi. Salah satu penyebab stunting adalah kurangnya pengetahuan ibu sehingga diperlukan edukasi yang efektif untuk mencegah terjadinya stunting. Tujuan dari pengabdian masyarakat ini adalah untuk meningkatkan pengetahuan ibu hamil, keluarga dan kader posyandu dalam pencegahan stunting melalui edukasi dengan metode yang digunakan edukasi melalui you tube, instagram dan webinar. Tahapan dalam pelaksanaan pengabdian pada masyarakat ini adalah pra lapangan untuk membuat rancangan, pelaksanaan edukasi melalui you tube, instragam dan webinar. Evaluasi dilakukan berdasarkan jumlah likes, view, followers, subscribe, hasil pre test dan post yang dianalisis berdasarkan uji wilcoxon. Setelah dilakukan edukasi melalui you tube tautan video https://youtu.be/V5fAtqbCpBU per tanggal 27 Februari 2021 jam 08.40 telah dilike 24 likes, view $47 \mathrm{x}$ ditonton 17 subcriber. Berdasarkan tautan video https://youtu.be/OBp6Rlxj7D8 per tanggal 26 Februari 2021 jam 22.06 telah dilike 20 orang 21 subscribe, instagram @imulaidaridini.id dengan followers 84 orang dengan total 421 likes. Berdasarkan hasil pre test post test terjadi peningkatan rata-rata pengetahuan sebelem edukasi 58,375 dan setelah edukasi 66,75 . Terdapat pengaruh edukasi terhadap pengetahuan peserta webiar ( $\mathrm{p}$ value 0,023 Hasil edukasi ini dapat diharapkan dapat ditindak lanjuti oleh kader posyandu dan petugas kesehatan untuk memantau pelaksanaan pencegahan stunting pada ibu hamil dan anak balita.
\end{abstract}

Kata kunci: edukasi; pencegahan; stunting

ABSTRACT. Stunting a chronic nutritional problem that occurs in children under five due to a lack of nutritional intake for a long time. Stunting impacts susceptibility to disease, suboptimal cognitive, motor and verbal development, body posture, learning capacity, school-age performance, productivity, work capacity, increased obesity and other diseases and a decline in the reproductive system. One of the causes of stunting is the lack of knowledge of the mother so that effective education is needed to prevent stunting. The purpose of this community service is to increase pregnant women, families and posyandu cadres knowledge in preventing stunting through education with the methods used by education through YouTube, Instagram and webinars. The stages in the implementation of this community service are pre-field to make designs, implement education through YouTube, instructionals and webinars. Evaluation is carried out based on the number of likes, views, followers, subscriptions, pre-test and post results which are analyzed based on the Wilcoxon test. After education is carried out via the YouTube video link https://youtu.be/V5fAtqbCpBU as of February 27, 2021 at 08.40 has been viewed 24 likes, views $47 x$ watched by 17 subscribers. Based on the video link https://youtu.be/OBp6Rlxj7D8 as of February 26, 2021 at 22.06, 20 people have subscribed 21 subscribers, Instagram @ imulaidaridini.id with 84 followers with a total of 421 likes. Based on the results of the pre test post test there is an increase in average- The average knowledge before education is 58.375 and after education is 66.75. There is an effect of education on the knowledge of webiar participants ( $p$ value 0.023. The results of this education can be expected to be followed up by posyandu cadres and health workers to monitor the implementation of stunting prevention in pregnant women and children under five.

Keywords: education; prevention; stunting

\section{PENDAHULUAN}

Stunting merupakan masalah gizi yang terjadi pada anak balita hal ini dibuktikan dengan masih tinggi angka kejadian stunting di Dunia pada tahun 2017 sebesar 22,2\% atau 150,8 juta balita dan lebih dari setengahnya (55\%) atau 83,6 juta balita terjadi di Asia. Menurut World Health Organization (WHO) prevalensi rata-rata stunting di Indonesia tahun 2017 sebanyak 36,4\% dan menempati urutan ke tiga tertinggi di Asia Tenggara setelah Timor Leste dan India. Berdasarkan hasil Riset Kesehatan Dasar (Riskesdas) 2018 angka stunting mengalami penurunan akan tetapi masih tinggi yaitu 23,6\% yang terdiri dari sangat pendek $6,7 \%$ dan $16,9 \%$ dan masih dibawah target WHO yaitu maksimal 20\% dan di Jawa Barat pada tahun 2017 kejadian stunting mencapai 29,6\% (Kemenkes, 2018).

Stunting merupakan keadaan gagal tumbuh yang dialami oleh anak di bawah lima tahun akibat kurang gizi sejak janin di dalam kandungan sampai awal bayi lahir akan tetapi baru nampak ketika anak sudah berusia dua tahun (TNP2K, 2017). Masa bayi dan anak adalah masa pertumbuhan dan perkembangan yang cepat dan sangat penting sebagai landasan yang menentukan kualias generasi penerus 
bangsa (Mitra, 2015). Anak balita yang mengalami stunting dapat berdampak tidak hanya jangka pendek tetapi dapat berdampak jangka panjang, dampak jangka pendek diantaranya mudah terkena penyakit yang dapat meningkatkan angka kesakitan dan kematian, tidak optimalnya perkembangan kognitif, motorik dan verbal sehingga akan meningkatkan biaya kesehatan. Sedangkan dampak jangka panjang diantaranya postur tubuh tidak optimal (lebih pendek dibandingkan anak pada umumnya), meningkatnya obesitas dan penyakit lain, menurunnya kesehatan sistem reproduksi, tidak optimalnya kapasitas belajar dan performa pada saat usia sekolah serta tidak optimalnya produktifitas dan kapasitas kerja (Kemenkes, 2018).

Salah satu faktor yang dapat mempengaruhi pertumbuhan anak khususnya bayi dan balita adalah status gizi, gizi yang baik akan meningkatkan kecerdasan anak. Kecerdasan, ketrampilan dan perkembangan serta pertumbuhan mental psikologi anak balita tidak lepas dari pertumbuhan dan perkembangan sel-sel otak. Agar otak anak berkembang secara optimal, peran orang tua adalah harus memenuhi kebutuhan zat gizi bagi anak sesuai kebutuhannya (Dewi \& Aminah, 2016). Salah satu dampak tidak terpenuhinya gizi pada anak dapat mengakibatkan stunting. Stunting pada anak merupakan dampak dari defisiensi nutrien selama seribu hari pertama kehidupan (70\%) dan usia 2-5 tahun (30\%) (Prendergast et al., 2014). Stunting dapat mengakibatkan gangguan perkembangan fisik anak yang irreversible, sehingga menyebabkan penurunan kemampuan kognitif, motorik dan penurunan performa kerja pada anak tersebut. Anak dengan stunting dapat memiliki rerata skor Intelligence Quotient (IQ) sebelas poin lebih rendah dibandingkan rerata skor IQ pada anak normal, kekurangan gizi pada anak jika tidak ditangani sedini mungkin dapat menimbulkan gangguan tumbuh kembang yang akan berlanjut hingga dewasa (Trihono et al., 2015).

Penyebab utama terjadinya stunting adalah kurangnya asupan nutrisi pada ibu hamil, masih rendahnya IMD dan pemberian ASI eksklusif, lemahnya pemantauan susu formula, belum semua tempat kerja menyediakan tempat untuk ibu menyusui, dan belum sesuainya pemenuhan kebutuhan gizi atau makanan pendamping ASI setelah bayi berumur 6 bulan (Kemenkes, 2018). Kurang gizi kronis karena kurangnya pengetahuan, pola asupan gizi yang di berikan ibu pada anak, pengetahuan ibu tentang pola asupan gizi dapat mempengaruhi terjadinya stunting (Olsa et al., 2018). Menurut Kusumawati et al.,(2015) faktor yang mempengaruhi terjadinya stunting diantaranya penyakit infeksi, sanitasi lingkungan, ketersediaan pangan keluarga, pelayanan kesehatan dan immunisasi, kurangnya pengetahuan ibu, rendahnya pendidikan dan pendapatan keluarga.

Menurut (Kemenkes, 2018) stunting dapat terjadi dimulai sejak masa pra konsepsi yaitu pada remaja putri yang mengalami anemia dan kurang gizi diperparah dengan asupan gizi yang kurang selama kehamilan, kesehatan ibu dan gizi ibu sebelum dan saat kehamilan, persalinan mempengaruhi postur tubuh ibu (pendek), jarak kehamilan yang terlalu dekat, ibu masih remaja, asupan nutrisi yang kurang selama kehamilan kerja. Oleh karena itu edukasi pada ibu hamil merupakan hal yang sangat penting dalam upaya meningkatkan pengetahuan dimana pada akhirnya dapat meningkatkan sikap dan perilaku positif pada ibu hamil untuk melakukan berbagai upaya dalam mencegah terjadinya stunting pada masa golden period atau 1000 hari pertama kehidupan. Berdasarkan kajian literatur yang dilakukan oleh (Mediani, 2020) terdapat berbagai prediktor terjadinya stunting pada anak balita di Indonesia diantaranya kurangnya pengetahuan ibu dan dari temuan juga menunjukan perlu dikembangkan promosi kesehatan terpadu pencegahan dan intervensi untuk mengurangi stunting. Hal ini sejalan dengan hasil penelitian (Nurarif \& Kusuma, 2015) bahwa tingginya angka kejadian stunting belum diimbangi dengan pengetahuan, sikap dan perilaku ibu hamil, dukungan keluarga dan kader posyandu dalam melakukan upaya pencegahan stunting sedini mungkin atau dalam 1000 hari pertama kehidupan (Nurarif \& Kusuma, 2015). Tujuan dari pengabdian pada masyarakat ini adalah untuk meningkatkan pengetahuan ibu hamil, keluarga dan kader posyandu dalam pencegahan stunting melalui edukasi.

\section{METODE}

Metoda dalam pengabdian pada masyarakat ini adalah edukasi melalui you tube, platform instagram @lawan stunting melalui instagram @imulaidaridini.id dan webinar dengan topik "Generasi Sehat Bebas Stunting". Pengabdian pada masyarakat ini dilaksanakan pada tanggal 11 Januari 2021 -10 Februari 2021 secara daring. Tahapan dalam pelaksanaan pengabdian pada masyarakat ini adalah pra lapangan untuk membuat rancangan pengabdian pada masyarakat, kegiatan lapangan yag terdiri dari identifikasi masalah dan sumber daya, pengolahan data dan analisis masalah dan sumber daya, persiapan instrumen untuk implementasi, pelaksanaan kegiatan dan evaluasi. Kegiatan pelaksanaan edukasi pencegahan stunting dilakukan melalui platform instagram @lawan stunting, instragam @Imulaidaridini.id, kanal you tube "Menuju Indonesia sadar Gizi', judul video "Edukasi Kebutuhan Gizi Ibu Hamil dan Anak Balita Untuk Mencegah Stunting" dengan tautan 
video https://youtu.be/V5fAtqbCpBU, "Edukasi Stunting Pada Ibu Hamil" dengan tautan video https://youtu.be/OBp6Rlxj7D8, video confrence dan webinar yang dilaksanakan tanggal 21 Januari 2021 menggunakan media zoom dengan link http:// bit.ly/WebinarEdukasiStunting. Seminar diikuti 40 peserta yang terdiri dari ibu hamil, keluarga dan kader posyandu dengan topik "Generasi Sehat Bebas stunting" dan sub topik "Kebutuhan gizi ibu hamil dan anak balita untuk mencegah stunting, deteksi dini dan pencegahan stunting, peran kader posyandu dalam mencegah stunting dan peran media sosial sebagai wadah edukasi stunting". Evaluasi kegiatan edukasi melalui you tube dihitung berdasarkan jumlah likes, view dan subscriber, instagram dihitung jumlah likes dan followers, sedangkan untuk webinar dilakukan pre test dan post test pada peserta untuk mengetahui pengetahuan peserta mengenai gizi untuk mencegah stunting, deteksi dini dan pencegahan stunting melalui google form. Untuk mengevaluasi signifikansi kegiatan webinar terhadap pengetahuan peserta mengenai stunting sebelum dan setelah mengikuti webinar dilakukan uji distribusi dan analisis inferensial dengan uji wilcoxon dan hasil yang didapatkan dipresentasikan dalam bentuk tabel.

\section{HASIL DAN PEMBAHASAN}

Edukasi pencegahan stunting pada ibu hamil melalui you tube tautan video https://youtu.be/ V5fAtqbCpBU per tanggal 27 Februari 2021 jam 08.40 telah dilike 24 likes, view $47 \mathrm{x}$ ditonton 17 subcriber. Berdasarkan tautan video https://youtu. be/OBp6Rlxj7D8 per tanggal 26 Februari 2021 jam 22.06 telah dilike 20 orang 21 subscribe. Edukasi melalui Edukasi juga dilakukan melalui instagram @ imulaidaridini.id dengan followers 84 orang dengan total 421 likes. Edukasi melalui webinar diikuti oleh 40 orang peserta terdiri dari ibu hamil, keluarga dan kader posyandu dengan hasil dapat dilihat pada tabel berikut.

Tabel 1. Distribusi Frekuensi Karakteristik Peserta Webinar $(n=40)$

\begin{tabular}{lcc}
\hline \multicolumn{1}{c}{ Variabel } & Frekuensi (f) & Persentase (\%) \\
\hline Umur & & \\
a. 20-25 tahun & 14 & 35 \\
b. 26-30 tahun & 14 & 35 \\
c. 31-40 tahun & 6 & 15 \\
d. > 40 tahun & 6 & 15 \\
Pendidikan & & \\
a. SLTP & 5 & 12,5 \\
b. SLTA & 15 & 37,5 \\
c. Perguruan Tinggi & 20 & 50 \\
Pekerjaan & & \\
a. Ibu Rumah Tangga & 23 & 57,5 \\
b. Pegawai Negeri Sipil & 2 & 5 \\
c. Mahasiswa & 15 & 37,5 \\
\hline
\end{tabular}

Tabel 1 menunjukan hampir setengahnya (35\%) peserta webinar berumur 20-25 tahun dan 2630 tahun, setengahnya (50\%) berpendidikan perguruan tinggi dan sebagian besar $(57,5 \%)$ bekerja sebagai ibu rumah tangga.

Tabel 2. Distribusi Frekuensi Pengetahuan Peserta Webinar Sebelum Dilakukan Edukasi ( $\mathrm{n}=40)$

\begin{tabular}{lcc}
\hline \multicolumn{1}{c}{ Pengetahuan } & Frekuensi (f) & Persentasi (\%) \\
\hline Baik & 2 & 5 \\
Cukup & 20 & 50 \\
Kurang & 18 & 45 \\
Total & 40 & 100 \\
\hline
\end{tabular}

Tabel 2 menunjukan pengetahuan peserta webinar sebelum dilakukan edukasi pencegahan stunting setengahnya (50\%) berpengetahuan cukup.

Tabel 3. Distribusi Frekuensi Pengetahuan Peserta Webinar Sesudah Dilakukan Edukasi $(n=40)$

\begin{tabular}{lcc}
\hline \multicolumn{1}{c}{ Pengetahuan } & Frekuensi (f) & Persentasi (\%) \\
\hline Baik & 8 & 20 \\
Cukup & 23 & 57,5 \\
Kurang & 9 & 22,5 \\
Total & 40 & 100 \\
\hline
\end{tabular}

Tabel 3 Menunjukan pengetahuan peserta webinar setelah dilakukan edukasi pencegahan stunting sebagian besar (57,5\%) berpengetahuan cukup.

Tabel 4. Hasil Uji Perbedaan Rata-rata Pengetahuan Peserta Webinar Tentang Pencegahan Stunting $(n=40)$

\begin{tabular}{lllllll}
\hline \multicolumn{1}{c}{$\begin{array}{c}\text { Tingkat } \\
\text { Pengetahuan }\end{array}$} & Min & Max & Median & Mean & SD & PValue \\
\hline $\begin{array}{l}\text { Sebelum } \\
\text { Edukasi }\end{array}$ & 30 & 80 & 60 & 58,375 & 12,267 & \\
$\begin{array}{l}\text { Sesudah } \\
\text { Edukasi }\end{array}$ & 35 & 90 & 70 & 66,75 & 11,654 & $\mathbf{0 , 0 0 2 3}$ \\
\hline
\end{tabular}

Tabel 4 menunjukan rata-rata pengetahuan sebelum edukasi pencegahan stunting 58,375 dan setelah dilakukan edukasi menjadi 66,75 serta didapatkan $p$ value 0,0023 , sehingga dapat dikatakan bahwa ada pengaruh pemberian edukasi terhadap pengetahuan mengenai pencegahan stunting pada peserta webinar.

Kegiatan pengabdian masyarakat melalui edukasi mengenai pencegahan stunting pada ibu hamil dilakukan secara virtual menggunakan media you tube, instragram dan webinar diikikuti oleh mitra secara antusias hal ini dapat dilihat dari banyaknya likes, view, subcriber dan followers melalui you tube dan isntragram. Pemaparan informasi ini membuat peserta menyadari bahwa pentingnya melakukan berbagai upaya untuk mencegah terjadinya stunting, demikian juga pada saat webinar yang dihadiri 
40 peserta sebagai mitra yang terdiri dari ibu hamil, ibu yang mempunyai anak balita dan kader Posyandu perserta sangat antusias untuk mengetahui pencegahan stunting hal ini dibuktikan dengan banyaknya pertanyaan yang diajukan oleh peserta. Edukasi tentang pencegahan stunting memiliki pengaruh terhadap peningkatan pengetahuan peserta, hal ini ditunjukan dari hasil analisis uji beda Wilcoxon bahwa nilai $p$ value kurang dari 0.05 artinya terjadi peningkatan pengetahuan dan pemahaman peserta tentang pencegahan stunting seseorang dalam memahami pentingnya pencegahan stunting.

Stunting merupakan suatu keadaan dengan tinggi badan kurang dibanding dengan tinggi standar usianya yang disebabkan asupan nutrisi yang kurang dalam waktu yang lama dan dapat berdampak pada terganggunya produktifitas pada saat dewasa karena anak yang stunting akan mengalami gangguan pertumbuhan fisik, kekebalan tubuh dan fungsi kognitif (Pusat Data dan Informasi Kemenkes RI, 2016). Anak dengan stunting beresiko lebih besar untuk tumbuh menjadi orang dewasa yang kurang berpendidikan, miskin, kurang sehat dan lebih rentan terkena penyakit. Anak stunting merupakan prediktor buruknya kualitas sumber daya manusia yang selanjutnya menurunkan kemampuan produktif suatu bangsa dimasa yang akan datang (Unicef/ WHO/The World Bank, 2019). Stunting selain disebabkan faktor kurangnya asupan nutrisi juga dapat disebabkan pengetahuan ibu yang kurang. Salah satu upaya untuk meningkatkan pengetahuan tentang pencegahan stunting dan faktor resiko terjadinya stunting dengan melakukan edukasi menggunakan media interaktif. Edukasi kesehatan merupakan upaya untuk menyampaikan informasi kesehatan kepada masyarakat sehingga dapat meningkatkan pengetahuan tentang kesehatan lebih baik. Oleh karena itu pemberian informasi tentang pencegahan stunting sangatlah penting sehingga kejadian stunting dapat berkurang (Maywita, 2015). Hasil penelitian (Kusumawati et al., 2015) tentang model pengendalian faktor resiko stunting pada Anak Usia di Bawah Tiga Tahun terdapat hubungan bermakna pengetahuan ibu dengan kejadian stunting dan pengetahuan ibu yang kurang baik beresiko meningkatkan 3,27 kali lebih besar kejadian stunting dibanding dengan pengetahuan ibu yang baik.

Hal ini sesuai dengan hasil penelitian (Listyarini \& Fatmawati, 2020) ada pengaruh edukasi tentang gizi ibu hamil dengan menggunakan media booklet terhadap perilaku pencegahan stunting di wilayah kerja Puskesmas Undaan Kabupaten Kudus. Pengetahuan mengenai gizi, merupakan suatu proses awal yang menentukan perubahan perilaku mengenai peningkatan status gizi, sehingga pengetahuan merupakan factor internal yang mempengaruhi perubahan perilaku. (Ekayanthi \& Suryani, 2019) hasil penelitian diketahui bahwa pelaksanaan edukasi pada kelas ibu hamil mempunyai pengaruh yang signifikan terhadap peningkatan pengetahuan ibu tentang pencegahan stunting. Sikap dan perilaku ibu selama hamil akan didukung oleh pengetahuan ibu tentang kehamilannya termasuk upaya pencegahan stunting. Seorang ibu yang memiliki pengetahuan dan sikap tentang gizi yang kurang akan berpengaruh terhadap status gizi kurang pada anaknya, akan tetapi jika pengetahuan ibu baik akan berupaya memilih menyediakan menu seimbang (Olsa et al., 2018). Timbulnya perilaku seseorang didasari oleh pengetahuan dan kesadaran serta sikap yang positif dari individu. Semakin tinggi pemahaman ibu hamil akan semakin baik dalam menyikapi kehamilannya (Wenas et al., 2014).

Dari hasil penelitian diketahui bahwa edukasi pada kelas ibu hamil mempunyai pengaruh yang signifikan terhadap peningkatan pengetahuan ibu tentang pencegahan stunting. Sikap dan perilaku ibu selama hamil didukung oleh pengetahuan ibu tentang kehamilannya(Ekayanthi \& Suryani, 2019). Kejadian stunting dapat dicegah salah satunya dengan pemenuhan kebutuhan zat gizi bagi ibu hamil. Kehamilan merupakan periode penting dalam pembentukan kualitas sumber daya manusia di masa yang akan datang. Pertumbuhan, perkembangan serta kesehatananaksangat ditentukan olehkondisijanin saat di dalam kandungan. Di Negara berkembang termasuk Indonesia masalah gizi masih merupakan masalah kesehatan masyarakat yang utama. Rendahnya status gizi ibu hamil selama kehamilan dapat mengakibatkan berbagai dampak tidak baik bagi ibu dan bayi (MCAI, 2016). Pemenuhan kebutuhan nutrisi ini berkaitan erat dengan tinggi rendahnya pengetahuan ibu hamil tentang gizi (Goni, 2013). Hal tersebut menunjukkan bahwa peningkatan pengetahuan ibu hamil termasuk tentang gizi sangat penting agar ibu hamil lebih memperhatikan kondisinya saat hamil terutama 316 Jurnal Kesehatan, Volume 10, Nomor 3, November 2019, hlm 312-319 makanan yang dikonsumsi untuk mencegah kejadian stunting. Selain tentang pemenuhan gizi, ibu juga perlu mengetahui tentang bagaimana penyiapan makanan dengan benar agar zat gizi dan kebersihannya terjaga dengan baik. Selain itu, faktor sanitasi dan kebersihan lingkungan berpengaruh untuk kesehatan ibu hamil dan tumbuh kembang anak.

Pentingnya pengetahuan tentang gizi ibu hamil dan bagaimana menyiapkan makanan yang benar dapat diperoleh dari petugas kesehatan (bidan) saat dilakukan kelas ibu hamil. Kelas ibu hamil merupakan sarana belajar bersama tentang kesehatan bagi ibu hamil dalam bentuk tatap muka dalam kelompok yang bertujuan untuk meningkatkan pengetahuan dan keterampilan ibu mengenai kehamilan, perawatan 
kehamilan, persalinan, nifas, serta bayi baru lahir. Dengan adanya kelas ibu hamil, ibu dapat mengetahui tentang pengaturan gizi saat hamil yang secara langsung meningkatkan pengetahuan ibu tentang pencegahan stunting. Hasil penelitian menunjukkan bahwa stunting dipengaruhi salah satunya oleh pengetahuan gizi ibu dan asupan ibu. Asupan ibu terutama saat hamil merupakan salah satu faktor yang berperan penting. Gizi janin bergantung sepenuhnya pada ibu, sehingga kecukupan gizi ibu sangat memengaruhi kondisi janin yang dikandungnya. Ibu hamil yang kurang gizi atau asupan makanan kurang akan menyebabkan gangguan pertumbuhan janin dalam kandungan (Picauly \& Toy, 2013). Asupan makanan selama hamil berbeda dengan asupan sebelum masa kehamilan.

Selain pengetahuan ibu peran kader kesehatan juga berpengaruh terhadap peningkatan status gizi bayi balita sehingga peningkatan pengetahuan kader kesehatan sangat diharapkan karena pengetahuan diperlukan sebagai dorongan fisik untuk menumbuhkan rasa percaya diri maupun sikap perilaku seseorang termasuk ibu hamil. Kader kesehatan diharapkan dapat mampu melakukan deteksi dini stunting dengan baik atau meningkat aspek psikomotornya dalam melakukan deteksi dini stunting untuk mencegah stunting lebih banyak difokuskan pada ibu hamil, hal tersebut sangat baik mengingat ibu hamil yang sudah mengetahui stunting dapat mencegah kejadian stunting (Adistie et al., 2018) Prosedur terpenting dari pencegahan dini adalah dilakukan screening rutin dan followup tinggi badan balita yang persisten. Program Posyandu yang dibuat oleh Pemerintah menjadi salh satu solusi nyata dan menjangkau seluruh lapisan masyarakat. Semakin baik pelayanan yang dilakukan di Posyandu sebanding dengan peningkatan mutu kesehatan masyarakat. Proses screening rutin tinggi badan/umur sebaiknya menjadi agenda wajib dalam setiap kegiatan yang dilaksanakan di posyandu (Setyowati \& Retno, 2015).

Peningkatan pengetahuan para kader kesehatan ini sangat diharapkan karena pengetahuan diperlukan sebagai dorongan fisik untuk menumbuhkan rasa percaya diri maupun sikap perilaku seseorang. Pengetahuan atau kognitif merupakan domain yang sangat penting dalam membentuk tindakan seseorang (overt behaviour) (Efendi, 2015). Berdasarkan beberapa hasil penelitian menunjukkan bahwa perilaku juga didasari oleh tingkat pengetahuan seseorang. Penelitian yang dilakukan oleh (Fatmah \& Nasution, 2012) menyimpulkan bahwa tingkat keterampilan kader posbindu dalam melakukan pengukuran antropometri tinggi badan prediksi lansia dan penyuluhan gizi seimbang dan hipertensi lansia berhubungan dengan peningkatan pengetahuan sebelum dan setelah pelatihan. Maka dari itu, para kader diharapkan dapat mampu melakukan dengan baik atau meningkat aspek psikomotornya dalam melakukan deteksi dini stunting setelah diberikan wawasan serta pengetahuan melalui kegiatan pelatihan. Peran aktif para kader kesehatan dalam membantu masyarakat untuk melakukan deteksi dini stunting serta stimulasi tumbuh kembang pada anak sehat dan melakukan kerjasama dengan pihak puskesmas dan dinas terkait untuk melakukan pelaporan memberikan kontribusi atas terwujudnya peningkatan derajat kesehatan masyarakat. anak dengan stunting atau berisiko stunting, serta anak dengan risiko penyimpangan atau gangguan tumbuh kembang dapat segera mendapatkan penanganan dengan cepat dan tepat sehingga dapat membantu mencegah atau meminimalisir dampak yang merugikan pada anak maupun keluarga serta menurunkan angka morbiditas. di wilayah tersebut. (Adistie et al., 2018).

\section{SIMPULAN}

Pelaksanaan pengabdian pada masyarakat tentang edukasi pencegahan stunting telah dilaksanakan dengan menggunakan media you tube, intagram dan webinar. Peserta edukasi terdiri dari ibu hamil, kader kesehatan dan masyarakat umum dan berjalan dengan lancar. Kegiatan yang telah dilakukan antara lain: pra lapangan untuk membuat rancangan, pelaksanaan edukasi melalui you tube, instragam dan webinar. Evaluasi dilakukan berdasarkan jumlah likes, view, followers, subscribe, hasil pre test dan post. Setelah dilakukan edukasi melalui you tube tautan video https:// youtu.be/V5fAtqbCpBU per tanggal 27 Februari 2021 jam 08.40 telah dilike 24 likes, view $47 \mathrm{x}$ ditonton 17 subcriber. Berdasarkan tautan video https://youtu. be/OBp6Rlxj7D8 per tanggal 26 Februari 2021 jam 22.06 telah dilike 20 orang 21 subscribe, instagram @imulaidaridini.id dengan followers 84 orang dengan total 421 likes dan berdasarkan hasil pre test post test terjadi peningkatan rata-rata pengetahuan sebelem edukasi dan setelah edukasi dan.terdapat pengaruh edukasi terhadap pengetahuan peserta webiar. Hasil edukasi ini dapat diharapkan dapat ditindak lanjuti oleh kader posyandu dan petugas kesehatan untuk memantau pelaksanaan pencegahan stunting pada ibu hamil dan anak balita.

\section{DAFTAR PUSTAKA}

Adistie, F., Lumbantobing, V. B. M., \& Maryam, N. N.A. (2018). Pemberdayaan Kader Kesehatan Dalam Deteksi Dini Stunting dan Stimulasi Tumbuh Kembang pada Balita. Media Karya Kesehatan. https://doi.org/10.24198/mkk. v1i2.18863 
Dewi, M., \& Aminah, M. (2016). Pengaruh Edukasi Gizi terhadap Feeding Practice Ibu Balita Stunting Usia 6-24 Bulan (The Effect of Nutritional Knowledge on Feeding Practice of Mothers Having Stunting Toddler Aged 6-24 Months). Indonesian Journal of Human Nutrition, 3(1), 1-8. https://doi.org/10.21776/ ub.ijhn.2016.003.suplemen.1

Efendi, D. (2015). Dasar-Dasar Pendidikan. DasarDasar PendEfendi, D. (2015). Dasar-Dasar Pendidikan. Dasar-Dasar Pendidikan, 7(9), 27-44.Idikan.

Ekayanthi, N. W. D., \& Suryani, P. (2019). Edukasi Gizi pada Ibu Hamil Mencegah Stunting pada Kelas Ibu Hamil. Jurnal Kesehatan. https:// doi.org/10.26630/jk.v10i3.1389

Fatmah, \& Nasution, Y. (2012). Peningkatan Pengetahuan dan Keterampilan Kader Posbindu dalamPengukuran Tinggi Badan Prediksi Lansia, Penyuluhan Gizi Seimbang dan Hipertensi Studi di Kecamatan Grogol Petamburan, Jakarta Barat. Media Medika Indonesiana.

Kementerian Kesehatan Republik Indonesia. (2018). Buletin Stunting. Kementerian Kesehatan Republik Indonesia, 301(5), 1163-1178.

Kusumawati, E., Rahardjo, S., \& Sari, H. P. (2015). Model Pengendalian Faktor Risiko Stunting pada Anak Bawah Tiga Tahun. Kesmas: National Public Health Journal. https://doi. org/10.21109/kesmas.v9i3.572

Listyarini, A. D., \& Fatmawati, Y. (2020). EDUKASI GIZI IBU HAMIL DENGAN MEDIA BOOKLET TENTANG PERILAKU PENCEGAHAN BALITA STUNTING DI WILAYAH PUSKESMAS UNDAAN KABUPATEN KUDUS. Jurnal Ilmu Keperawatan Dan Kebidanan.

Maywita, E. (2015). Risk Factors Cause the Stunting of Age 12-59 Months in Kampung Baru Kec. Lubuk Begalung in. In Jurnal Riset Hesti Medan.

Mediani, H. S. (2020). Predictors of Stunting Among Children Under Five Year of Age in Indonesia: A Scoping Review. Global Journal of Health Science. https://doi.org/10.5539/ gihs.v12n8p83

Mitra,M.(2015). Stunting Problemsand Interventions to Prevent Stunting (A Literature Review). Jurnal Kesehatan Komunitas, 2(6), 254-261. https://doi.org/10.25311/jkk.vol2.iss6.85
Nadhiroh, Siti Rahayu; Ni'mah, K. (2010). Faktor yang berhubungan dengan kejadian. Media Gizi Indonesia, 1, 13-19.

Olsa, E. D., Sulastri, D., \& Anas, E. (2018). Hubungan Sikap dan Pengetahuan Ibu Terhadap Kejadian Stunting pada Anak Baru Masuk Sekolah Dasar di Kecamanatan Nanggalo. Jurnal Kesehatan Andalas. https:// doi.org/10.25077/jka.v6i3.733

Picauly, I., \& Toy, S. M. (2013). ANALISIS DETERMINAN DAN PENGARUH STUNTING TERHADAP PRESTASI BELAJAR ANAK SEKOLAH DI KUPANG DAN SUMBA TIMUR, NTT. Jurnal Gizi Dan Pangan. https://doi.org/10.25182/ jgp.2013.8.1.55-62

Prendergast,A. J., Rukobo, S., Chasekwa, B., Mutasa, K., Ntozini, R., Mbuya, M. N. N., Jones, A., Moulton, L. H., Stoltzfus, R. J., \& Humphrey, J. H. (2014). Stunting is characterized by chronic inflammation in zimbabwean infants. PLoS ONE, 9(2). https://doi.org/10.1371/ journal.pone. 0086928

Pusat Data dan Informasi Kemenkes RI. (2016). Infodatin: Situasi Balita Pendek. $A C M$ SIGAPL APL Quote Quad.

Setiawan, E., Machmud, R., \& Masrul, M. (2018). Faktor-Faktor yang Berhubungan dengan Kejadian Stunting pada Anak Usia 24-59 Bulan di Wilayah Kerja Puskesmas Andalas Kecamatan Padang Timur Kota Padang Tahun 2018. Jurnal Kesehatan Andalas, 7(2), 275. https://doi.org/10.25077/jka.v7.i2.p275284.2018

TNP2K. (2017). 100 Kabupaten/Kota Prioritas untuk Intervensi Anak Kerdil (Stunting): Tim Nasional Percepatan Penanggulangan Kemiskinan. In Jakarta.

Trihono, Atmarita, Tjandrarini, D. H., Irawati, A., Utami, N. H., Tejayanti, T., \& Nurlinawati, I. (2015). Pendek (Stunting) di Indonesia, Masalah dan Solusinya. In Lembaga Penerbit Balitbangkes. https://doi.org/hrfh

Unicef/ WHO/The World Bank. (2019). Levels and Trends in Child malnutrition - Joint Child Malnutrition Estimates. Unicef.

Wenas, R., Lontaan, A., \& Korah, B. (2014). Pengaruh Promosi Kesehatan Tentang Tanda Bahaya Kehamilan Terhadap Pengetahuan Ibu Hamil Di Puskesmas Amurang Kabupaten Minahasa Selatan. Jurnal Ilmiah Bidan. 